\title{
Is the VITAMINS RCT indicating potential redundancy between corticosteroids and vitamin C?
}

\author{
Anitra C. Carr
}

Since the publication of the retrospective before and after study by Dr. Marik and colleagues, in which administration of hydrocortisone, intravenous (IV) vitamin C, and thiamine was indicated to provide a survival advantage in septic patients [1], there has been a prevalence of clinical trials of variable quality and subsequent meta-analyses indicating variable outcomes [2]. Unlike previous combination trials, which did not control for corticosteroid use in the control arm, the recently published VITAMINS randomized clinical trial standardized corticosteroid administration in the control arm to determine if IV vitamin C and thiamine could provide an additional survival advantage over hydrocortisone alone [3]. This trial showed no benefit of the combination of hydrocortisone, IV vitamin $\mathrm{C}$, and thiamine in comparison to hydrocortisone alone.

Although the accompanying editorial by Dr. Kalil suggested that in light of this finding, IV vitamin $C$ has no place in critical care, limitations of the VITAMINS trial preclude this view. It is well established that septic patients exhibit a high prevalence of vitamin $\mathrm{C}$ deficiency, and a recently published clinical trial in JAMA indicated that IV vitamin $C$ may provide a survival advantage in these patients [4]. Since the VITAMINS trial did not include an arm with IV vitamin $C$ monotherapy, this trial does not provide any information as to whether IV vitamin $\mathrm{C}$ is of benefit to septic patients in the absence of corticosteroid administration. This trial simply indicated that short-term IV vitamin $C$ administration (mean of 3.4 days) may not be of additional benefit if corticosteroids are being administered to the patients. However, routine corticosteroid

Correspondence: anitra.carr@otago.ac.nz

Department of Pathology \& Biomedical Science, University of Otago,

Christchurch, PO Box 4345, Christchurch 8140, New Zealand administration to septic patients is not a common clinical practice in all intensive care units.

Indeed, the VITAMINS trial may in fact indicate redundancy between vitamin $\mathrm{C}$ and corticosteroids. Vitamin $C$ is thought to play a role in the stress response as evidenced by its very high concentrations in the adrenal glands and its release in response to ACTH [5]. Furthermore, animals that cannot synthesize vitamin $C$ have significantly elevated cortisol release in response to stress compared with animals that can synthesize vitamin $\mathrm{C}$ endogenously (reviewed in [5]). Thus, administration of corticosteroids to septic patients may help compensate for deficient vitamin $\mathrm{C}$ concentrations in these patients. Alternatively, in the absence of corticosteroid administration, supplementation of deficient patients with vitamin C may help with their stress response and could potentially provide a survival advantage, particularly in patients with HPA axis dysregulation.

\section{Acknowledgements \\ ACC is the recipient of a Health Research Council of New Zealand Sir Charles Hercus Health Research Fellowship.}

\section{Author's contributions}

ACC wrote the letter. The author read and approved the final manuscript.

\section{Funding}

None

Availability of data and materials

N/A

\section{Ethics approval and consent to participate}

N/A

\section{Consent for publication}

N/A

Competing interests

None 
Received: 15 March 2020 Accepted: 25 March 2020

Published online: 06 April 2020

\section{References}

1. Marik PE, Khangoora V, Rivera R, Hooper MH, Catravas J. Hydrocortisone, vitamin $C$, and thiamine for the treatment of severe sepsis and septic shock: a retrospective before-after study. Chest. 2017;151(6):1229-38.

2. Carr AC. Vitamin C administration in the critically ill: a summary of recent metaanalyses. Crit Care. 2019;23:265. https://doi.org/10.1186/s13054-019-2538-y.

3. Fujii T, Luethi N, Young PJ, Frei DR, Eastwood GM, French CJ, Deane AM, Shehabi Y, Hajjar LA, Oliveira G, Udy AA, Orford N, Edney SJ, Hunt AL, Judd HL, Bitker L, Cioccari L, Naorungroj T, Yanase F, Bates S, McGain F, Hudson EP, AlBassam W, Dwivedi DB, Peppin C, McCracken P, Orosz J, Bailey M, Bellomo R. Effect of vitamin C, hydrocortisone, and thiamine vs hydrocortisone alone on time alive and free of vasopressor support among patients with septic shock: the VITAMINS randomized clinical trial. JAMA. 2020. https://doi.org/10.1001/ jama.2019.22176.

4. Fowler AA 3rd, Truwit JD, Hite RD, Morris PE, DeWilde C, Priday A, Fisher B, Thacker LR 2nd, Natarajan R, Brophy DF, Sculthorpe R, Nanchal R, Syed A, Sturgill J, Martin GS, Sevransky J, Kashiouris M, Hamman S, Egan KF, Hastings A, Spencer W, Tench S, Mehkri O, Bindas J, Duggal A, Graf J, Zellner S, Yanny L, McPolin C, Hollrith T, Kramer D, Ojielo C, Damm T, Cassity E, Wieliczko A, Halquist M. Effect of vitamin C infusion on organ failure and biomarkers of inflammation and vascular injury in patients with sepsis and severe acute respiratory failure: the CITRIS-ALI randomized clinical trial. JAMA. 2019;322(13):1261-70

5. Hooper $\mathrm{MH}$, Carr A, Marik PE. The adrenal-vitamin C axis: from fish to guinea pigs and primates. Crit Care. 2019;23(1):29. https://doi.org/10.1186/ s13054-019-2332-x

\section{Publisher's Note}

Springer Nature remains neutral with regard to jurisdictional claims in published maps and institutional affiliations. 